\title{
Does Adaptive Strategy for Delayed Seed Dispersion affect Extinction Probability of a Desert Species? an Assessment using the Population Viability Analysis and Glass House Experiment
}

\author{
Manish Mathur* \\ Plant Ecology Laboratory; Jai Narain Vyas University; Jodhpur, Rajasthan - India
}

\begin{abstract}
Canopy seed bank is an important adaptive evolutionary trait that provides various types of protection to the seeds. However, costing of such evolutionary trait on plant survival is largely unknown. Present investigation provided a new insight on the serotonious habit of Blepharis sindica associated with its endangerment status. Extinction probabilities of two available population of $\mathrm{B}$. sindica were quantified using two types of census data, i.e., fruiting body number and actual population size. Population Viability Analysis (PVA) revealed that delayed seed release tendency (higher fruiting body number) was not synchronized with actual ground conditions (lower population size). PVA analysis based on actual population size indicated that both the available populations would vanish within 20 years. The mean time of extinction calculated from both type census data indicated its extinction within 48 years. For assessing the conservation criteria, a glass house experiment was carried out with different soil types and compositions. Pure sand and higher proportions of sand-silt were more suitable compared to clay; further, gravelly surface was the most unsuitable habitat for this species. Collection of the seeds from mature fruits/capsule and their sowing with moderate moisture availability with sandy soil could be recommended.
\end{abstract}

Key words: Blepharis sindica, Population Viability Analysis (PVA), Serotiny, Cumulative Probability of Extinction, Mean Extinction Time, Hydrate Mucilage

\section{INTRODUCTION}

Delay in seed release, leading to formation of an aerial seed bank is one way to deal with uncertainties of the environment (Thanos 2004). In the arid desert habitats, delay in seed release associated with continuous supply of resources to seed and also to ensure the long occupancy of plant at favorable habitats (Ma et al. 2010). In general, the retention of seeds in the plant canopy for one to 30 years or more is termed as serotiny (Lamont et al. 1991). It is common in fluctuating environments such as dry, fire-prone scrubs and forests (Peters et al. 2009). Plants are either non- serotinous, weakly serotinous (most seeds released within a few years) or strongly serotinous (most seeds still retained after a few years). Serotiny is derived from the Latin word serotinus, meaning late in occurrence and through this strategy mature seed released after a specific period of time and conditions, resulting in the build-up of a canopy stored seed bank.

For adopting the delayed seed release as a successful evolutionary option, five conditions must be satisfied: (1) presence of a peculiar reproductive structure that may store and protect the seeds from granivores, pathogen and other

*Author for correspondence: ravi_mm2099@yahoo.com 
unfavourable environmental conditions, (2) higher canopy seed viability, (3) operation of the seed release mechanism must be cued to the onset of conditions conducive to seedling establishment and recruitment, (4) mean timing of the cue for seed release must occur within the mean reproductive lifespan of the species, and (5) there must be the genetic capacity and enough opportunity to produce and store enough seed in the mean interval among cueing events to ensure population replacement in the next establishment phase. Lamont et al. (1991) have reported around 530 serotinous species in 40 woody genera and most of them confined in families such as casuarinaceae, proteaceae, myrtaceae, aseteraceae, ericaceae, bruniaceae and cupressaceae. For the function of serotiny, there were nine hypothesis were presented that related with (1) seed storage maximizes seed available for the next generation in fire prone vegetation; (2) seed storage dampens fluctuation in the annual seed crop assure adequate seedling establishment following fire; (3) serotiny maximizes seedling establishment because the biology of the species depends on dense mono-specific stands; (4) Immediate postfire release ensures seeds arrive on the optimal substrate for germination and establishment; (5) synchronized seed release leads to post-dispersal predator satiation which ensures seedling establishment; (6)Seed release is delayed until conditions (post fire) favour dispersal by wind; (7) because seeds are short lived after release, immediate post fire dispersal ensures that the interval between release and optimal conditions for establishment is minimized; (8) post fire dispersal ensures seeds are ideally located in the soil to take advantage of growing -season rains, and (9) canopy seed storage ensures minimal seed death from the fire required to create conditions suitable for germination. All these hypothesis dealt with the surrounding conditions of aerial seed bank, but these hypotheses were not exercised for establishing the correlation between the frequency of seed release and frequency of successful new progeny. Further, such hypotheses were much generalized and they were not evaluated for those species that had a specific seed structure, which required a species specific favourable ground conditions.

Seed predation by the rodents and harvester ants is often intense in deserts, and is recognized as a major factor controlling seed pool dynamics (Inouye et al. 1980; Morton 1985 and Narita
1998). Formation of an aerial seed pool may reduce the damage by the predation. Thus, the seed holding habit in desert plants should be assessed in terms of both seed release timing and predation avoidance (Ellner and Shmida 1981). Some desert annuals having strong lignified stems, which remain standing for several years, carry a persistent aerial seed pool (Gutterman 1993; Günster 1994 and Gutterman and Ginott 1994). Because the construction of the tough structure requires additional resources, there may be reduction of resource allocation to reproduction.

Thus, from above literature review it is emerged that serotiny is being adapted by many species to cope-up with the unfavourable surroundings and conclusively it's a recognition ability of a species to recognize the correct cue or triggering effect. However, quantification of costing of such evolutionary adaptation is largely unknown, particularly for some of the rare, endangered and threatened plants. Habitat loss and fragmentations are the largely known casual factors for the extinction of many plant species, while other factors such as over-harvesting, fire, flood, etc, are also well studied factors. But the relationship between the adoption of an evolutionary trait and the threat status of a plant species is largely unknown.

The present investigation quantified how a adaptive strategy (serotiny) affecting the survival potential of an endangered desert plant Blepharis sindica and subsequently its relation with the decreasing population of this species. The main objectives were (1) assessment of population viability analysis of this species by using two contrasting parameters (as a census count), i.e., number of fruiting bodies and actual population size availability, (2) assessing the performance of this species, in particular soil types and their different mixtures. This exercise was carried out to know the ground conditions that affect the actual population size after dispersal.

Blepharis sindica, locally known as 'Bhangari" is a small serotinous, dichotomously branched woody annual having short stem, sessile leaves and fruit in the form of capsule (Fig. 1A). Each capsule contains two seeds and each seed is covered with hygroscopic hairs on its surface. The survivorship pattern showed high mortality during early phase of life cycle that was associated with moisture availability. Aziz and Khan (1993) considered this plant under type III Deevey curve. 
Narita (1998) studied the germination, growth, phenology, and survivorship strategies and seed production in B. sindica. Narita and Wada (1998) studied seed release, predation and germination patterns of this plant. They concluded that the aerial seed holding on the dead plants (Fig. 1B) was a way to avoid seed predation in harsh desert environments where seed predation was intense and favourable periods for the growth were temporally limited and unpredictable. Phytochemistry, clinical validation and agro-techniques have been studied by Mathur and Sundaramoorthy (2005). Habitat loss is the major thereat associate with its current endangered status (Tripathi and Arya 2002).

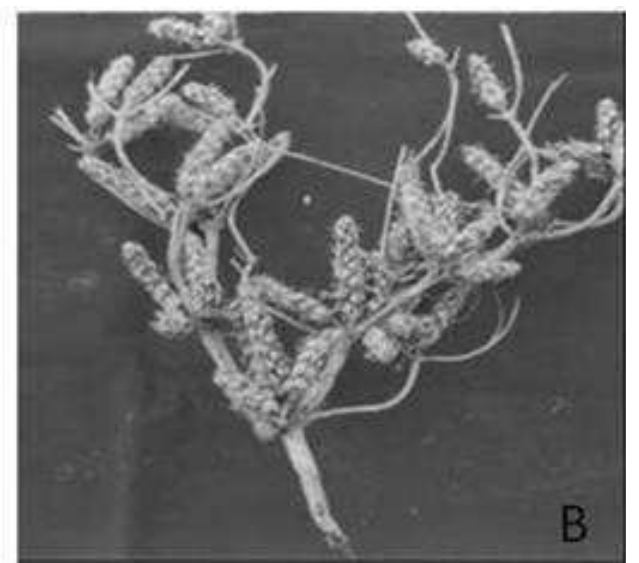

Figure1 - Blepharis sindica at natural habitat (A), dead plant with canopy seed storage (B).

\section{MATERIAL AND METHODS}

Two available contrasting sites were selected. Pure stand (Population one) was located on hummocky undulating terrains while the mixed stand (Population two) was located on older alluvial plain with other associated grasses such as
Dactyloctenium aegyptium, Eragrostis ciliaris, Aristida funiculate, Lasiurus sindicus and a woody perennial Tephrosia purpurea that represent the sub-climax stage of habitats (Saxena and Aggarwal 1983). The geographical coordinates and soil compositions are presented in Table1.

Table 1 - GPS locations and habitat types of two populations.

\begin{tabular}{|c|c|c|c|c|c|c|c|}
\hline & \multicolumn{2}{|c|}{ Coordinates } & \multirow[t]{2}{*}{ Habitat types } & \multicolumn{4}{|c|}{ Soil Textures } \\
\hline & $\mathbf{N}$ & $\mathbf{E}$ & & Clay & Silt & Sand & Gravel \\
\hline & $26^{0} 12^{\prime} 29.5^{\prime \prime}$ & $73^{0} 04^{\prime} 24.8^{\prime \prime}$ & Hummock undulating terrains, unprotected & 28 & 4.33 & 66.07 & 1.105 \\
\hline Population 2 & $26^{0} 15^{\prime} 1.8^{\prime \prime}$ & $73^{0} 59^{\prime} 29.8^{\prime \prime}$ & Old alluvium plains, protected & 29.61 & 1.35 & 68.78 & 0.255 \\
\hline
\end{tabular}

To assess the future prospects of this species, population viability analysis was carried out by simple count method (Morris et al. 1999). The PVA was quantified based on the fruiting body number as well as on population size. Data regarding the fruiting body number, actual population size and as well as edaphic and community parameters were collected from 1 to 48 months (with the gap of six month each). Morris et al. (1991) method is based on the diffusion approximation model that assumes that the natural logarithm of the population size is adequately approximated by a Wiener process with drift and originates from the observation at the population level, stochastic age- structured models with no density dependence behave as a stochastic, discrete time model with exponential growth or decline (Jacquemyn et al. 2007).

$N_{t+1}=N_{t}(\pi \tau+\varepsilon)$ Where $\varepsilon \sim \mathrm{N}\left(0, \sigma^{2} \tau\right)$

The parameter $\pi$ determines the rate at which the median increases through the time, whereas $\sigma$ determines the rate of spread of the distribution, or the variability of population size at time $t+\tau$. When the censuses are conducted at certain period 
of time gap and there are no missing census points, the maximum likelihood estimates of $\pi$ and $\sigma^{2}$ are

$$
\begin{aligned}
& \pi=\text { mean }\left[\ln \left(\frac{N_{t+1}}{N_{t}}\right)\right] \\
& \sigma^{2}=\operatorname{var}\left[\ln \left(\frac{N_{t-1}}{N_{t}}\right)\right]
\end{aligned}
$$

Based on these measures the average value of the population growth rate and its confidence interval can be calculated as

$$
\begin{aligned}
& \hat{\lambda}=\exp \left[\hat{\pi}\left(\frac{\sigma^{2}}{2}\right)\right] \\
& \exp \left(\hat{r} \pm Z_{\frac{\hat{\alpha}}{2}} \sqrt{\left.\hat{\sigma^{2}}\left[\frac{1}{t_{Q}}+\frac{\overrightarrow{\sigma^{2}}}{2(q-1)}\right]\right)}\right.
\end{aligned}
$$

Where $\mathrm{q}+1$ is the number of censuses and $\frac{Z_{\frac{\alpha}{2}}}{2}$ is the $100\{1-(\bar{\alpha} / 2)]$ the percentile of the standard normal distribution. The probability that extinction has occurred at some time, can be approximated by the probability that $X(\tau) \geq x_{d}$ at some time $\tau \leq T$ where $x_{d}=\log \left(n_{q} / n_{e}\right)$ and $n_{e}$ is the quasi- extinction threshold. This probability can be expressed as

$\operatorname{Pr}[\tau \leq T)=\phi(U-V)+\exp (2 U V) \phi(-(U+V))$

Where $\phi$ is the standard normal cumulative distribution function, and

$$
U=|\hat{\pi}| \sqrt{\frac{T}{\sigma}} \quad \text { and } V=\frac{x_{d}}{\sigma \sqrt{T}}
$$

The most recent population count was used as initial population size $\mathrm{n}_{\mathrm{q}}$, and two quasi-extinction threshold $\left(\mathrm{n}_{\mathrm{e}}\right)$ were used. Dennis et al (1991) have shown that the probability of extinction can be calculated as

$$
\hat{\pi}=\left(\frac{n_{Q}}{n_{Q}}\right) \frac{2 \pi}{\sigma^{2}}
$$

and the mean time of extinction as

$$
0=\frac{x_{d}}{|\hat{\pi}|}
$$

The median time to extinction was derived from the cumulative distribution function.

Seed water retention capacity was majored with imbibitions test. This test was conducted from 1 second to 300 second and percent imbibition was calculated according to Baskin et al. (2004). The nursery was established by using black poly bags containing different soil types (sand, clay, and gravel) and soil mixtures (sand clay and silt) in $1: 1: 1,1: 2: 1,2: 1: 2$ and 2:2:1 ration). Parameters such as percent germination, percentage survival were recorded after $7^{\text {th }}$ day of seed sowing, while seedling quality index (SQI), reproductive capacity and aggressive capacity were calculated at the end of growing season (i.e., after four months).

Seedling quality index (SQI) estimated using formula of Dickson et al. (1960)

$$
\text { Total Weight of the plant(g/plant) }
$$

$\mathrm{SQI}=[($ Height $(\mathrm{cm})$ root collar diameter $(\mathrm{mm})]+[$ shoot wejight $(\mathrm{g} / \mathrm{plant}) /($ root weight $(\mathrm{g} / \mathrm{plant})]$

Reproductive capacity was quantified as per Salisbury (1942) as the product of average seed out- put and the fraction represented by the average germination. Aggressive capacity (AC), which denoted the potentiality of species to colonies and spread in nature, was calculated following formula. $\mathrm{AC}=$ Average reproductive capacity $\mathrm{X}$ percentage survival of seedling in nature. All the experiments were executed using the RBD design.

\section{RESULTS AND DISCUSSION}

Range of various edaphic and community composition parameters during the study period are present in Table 2.

Table 2 - Various parameters at Blepharis sindica locations during study period.

\begin{tabular}{cll}
\hline Parameters & & Range \\
\hline $\begin{array}{l}\text { Soil } \\
\text { Compositions }\end{array}$ & $\begin{array}{l}\text { Organic Carbon } \\
\left(\mathrm{mg} \mathrm{100g}^{1}\right)\end{array}$ & $62.86-203.5$ \\
& $\begin{array}{l}\text { Total Nitrogen } \\
\left(\mathrm{mg} \mathrm{100g}^{1}\right)\end{array}$ & $34.38-82.49$ \\
& $\mathrm{C} / \mathrm{N}$ Ration & $0.36-5.91$ \\
& Moisture & $0.48-11.38$ \\
& pH & $6.23-8.56$ \\
& Electric & $0.11-0.23$ \\
\hline Community & Richness & $2-10$ \\
& Shannon Weiner & $0.65-2.1$ \\
& Relative & $16.27-62$ \\
& Evenness & $0.85-1.01$ \\
& Simpson Index & $0.13-0.53$ \\
\hline
\end{tabular}

Based on the fruiting body census, both the population 1 and 2 had average rate of increase $(\lambda>1) 1.03$ and 1.02 with $95 \%$ confidence interval 0.97 to 0.99 and 0.93 to 1.02 , respectively. The fruiting body number (retained fruiting structure for this species) indicated that the populations 
were increasing. Based on actual population size census, contrasting results of average rate of increase $(\lambda)$ for both populations were recorded $(\lambda<1)$, which were 0.83 and 0.91 with $95 \%$ confidence interval 0.93 to 1.02 to 0.91 to 1.01 , respectively. Thus, it was concluded that this species utilized serotiny habit as an evolutionary trait to protect the seed from the predators and other non-conducive surrounding. However, quantitative parameters such as fruiting number were not transmitted in to new seedling and decline in population size was recorded. Further, ultimate extinction probability (based on actual population size) was also recorded higher for both the population (1 and 0.86), compared to the number of fruiting body (0.044 and 0.066, respectively).

With the two different parameters for PVA quantification, a large variation was recorded in mean time of extinction. Based on fruiting body, the mean time of extinction was almost four times higher (40 years) for the population one as compared to actual population size (10 years); similarly, it was recorded 2.5 time more for the population two (Table 3 ).

Table 3 - Population Viability Analysis based on fruiting body number and actual population size.

\begin{tabular}{|c|c|c|c|c|}
\hline \multirow{2}{*}{ Parameters } & \multicolumn{2}{|c|}{ PVA Based on Fruiting Body } & \multicolumn{2}{|c|}{ PVA Based on Population Size } \\
\hline & Population 1 & Population 2 & Population 1 & Population 2 \\
\hline Average finite range of increase $(\lambda)$ & 1.037 & 1.02 & 0.83 & 0.91 \\
\hline Confidence limit (95\%) Lower and Upper & 0.97 to 0.99 & 0.93 to 1.02 & 0.93 to 1.02 & 0.91 to 1.01 \\
\hline Extinction threshold & 0.044 & 0.066 & 1 & 0.86 \\
\hline Mean time of extinction (Months/Year) & $486 / 40$ & $396 / 33$ & $117 / 10$ & $159 / 13$ \\
\hline Confidence limit (95\%) Lower and Upper & 0 to 1770.99 & 0 to 8783.77 & 0 to 779.75 & 0 to 1317.38 \\
\hline $\begin{array}{l}\text { Median time when extinction occurs, } \\
\text { Months/Year (A) }\end{array}$ & $470 / 39$ & $350 / 29$ & $100 / 8$ & $140 / 12$ \\
\hline Probability of extinction, Months/Year (B) & $900 / 75$ & $440 / 37$ & $160 / 13$ & $200 / 17$ \\
\hline $\begin{array}{l}\text { Number of years at which there is only a } 5 \% \\
\text { chance of population percistence, Months/Year (C) }\end{array}$ & $760 / 63$ & $430 / 36$ & $150 / 12$ & $210 / 17$ \\
\hline
\end{tabular}

Figure 2 (based on fruiting body numbers) and Figure 3 (based on actual population size) showed cumulative probability of extinction (CDF). From these figures various parameters like (1) Median time when extinction occurs, Months/Year, A, (2) Probability of extinction, Months/Year, B and (3) Number of years at which there is only a $5 \%$ chance of population percistence, Months/Year, C can be calculated (Table 3). All these three parameters suggested that population one (size base) is more prone for extinction compared to population two, however when CDF parameters calcualted with using fruiting body, it shows reverse extinction trends.

Positive linear regression was recorded between the mean fruiting body and probability of extinction (Probability of Extinction $=279.66+$ 1.99 Mean Fruiting Body, $\mathrm{R}^{2}=1.00^{* *}$ ). A negative linear regression was recorded between the mean population size and probability of extinction (Probability of Extinction $=367.52+-4.0$ Mean Population Size, $\mathrm{R}^{2}=1.00^{* * *}$ ). Thus, the present investigation provided a new insight that how the adaptation of a particular trait (serotiny) coasted a species and accelerated its extinction chances. In this case, it could be interpreted that although the plant possessed sufficient reproductive output, which was triggered or cued by rainfall events, but such conducive pulses forced this species to disperse the seed when the actual ground conditions were not favourable for its germination and survival. Mathur (2005 and 2006) reported that at excess water (high soil moisture) conditions, the hydrated mucilage arised from the surface of seed, which inhibited the germination.

Thus, it could be concluded that beside the habitat loss, plant physiological trait (serotiny) was also an associated factors with the extinction probability of $B$. sindica. The variation in different PVA parameters between the population one and two with using the fruiting body as a census count could be explained by density dependent inhibitory factor that was imposed on reproductive output of the plant. The site of the population one had lowers diversity and higher niche area availability compared to site two. At site two, the other co-dominant associates were Lasiurus sindicus, Tephrosia purpurea. 

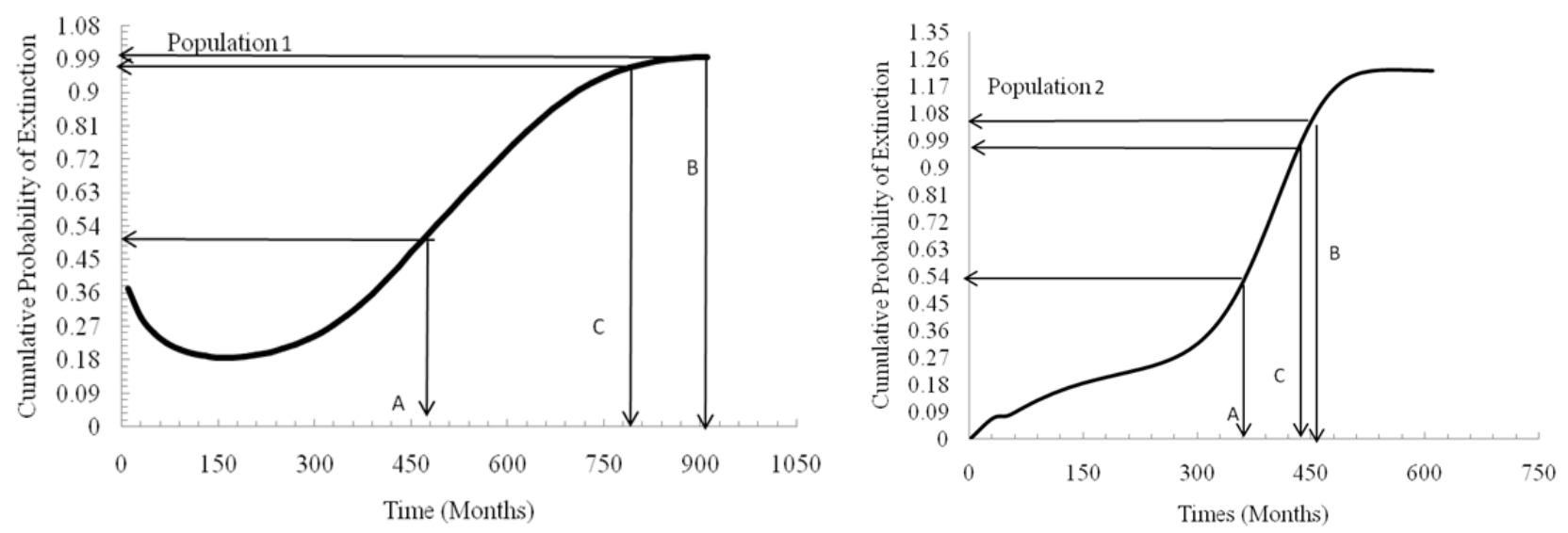

Figure 2 - Cumulative Probability of Extinction of Population one and Two (Based on Fruiting Body Numbers).
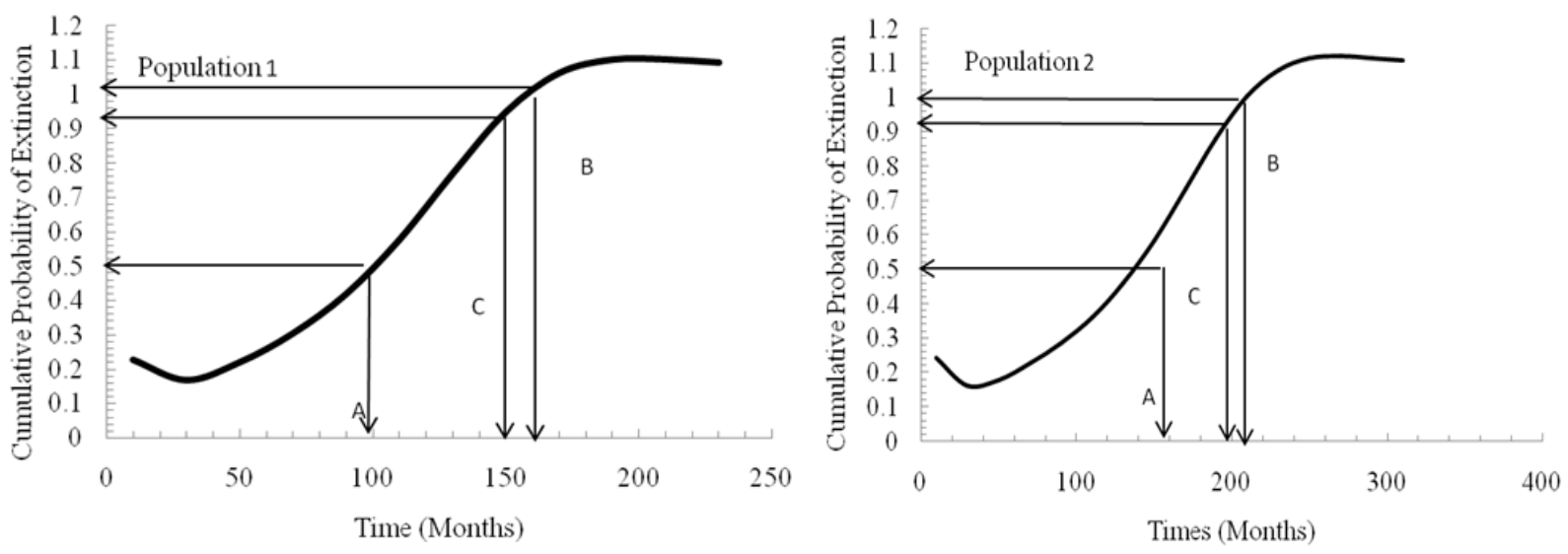

Figure 3 - Cumulative Probability of Extinction of Population one and Two (Based on Population Size).

Regression analysis between the mean of diversity index (Shannon and Weiver index) and mean fruiting body proved this negative relation (Mean Fruiting Body $=728.25+-404.88$ Diversity Index $\left.\mathrm{H}^{\prime}, \mathrm{R}^{2}=1.00^{* *}\right)$. Similarly variation in different PVA parameters between the population one and two using the population size as a census count could be explained by adoption of management approaches for population two. This population was completely free from grazing and other anthropogenic activities and that's why this population was larger than other.

To validated the present findings, imbibitions study and a glass house experiment with various soil types and their different mixtures were conducted. Imbibitions study revealed that seed imbibed the higher amount of water rapidly and attained equilibrium within 50 seconds (Percent Imbibitions $=40.893$ Time in Seconds ${ }^{\wedge .3942}, \mathrm{R}^{2}=$ $\left.0.977^{* *}\right)$. Glass house experiment revealed that among the pure soil types, sandy soil supported the higher $\%$ germination and \% survival, total biomass, SQI, average reproductive capacity and aggressive capacity compared to the clay and gravel types. Subsequently, the impact of different soil mixture (sand: clay: silt) on various parameters were quantified, which revealed that higher proportion of sand and silt favoured most parameters compared to clay type (Table 4). The ANOVA revealed the significant impact of various soil types and their mixtures $\left(T_{4}\right.$ to $\left.T_{7}\right)$ on various seedling parameters (Table 5 ). 
Table 4 - Various seedling parameters in different soil types and their various compositions.

\begin{tabular}{lcccccc}
\hline Soil Type & $\begin{array}{c}\text { \% } \\
\text { Germination }\end{array}$ & $\begin{array}{c}\text { \% } \\
\text { Survival }\end{array}$ & $\begin{array}{c}\text { Total } \\
\text { Biomass }\end{array}$ & SQI & $\begin{array}{c}\text { Average Reproductive } \\
\text { Capacity }\end{array}$ & $\begin{array}{c}\text { Aggressive } \\
\text { Capacity }\end{array}$ \\
\hline Sand $\left(\mathrm{T}_{1}\right)$ & 79.44 & 46.83 & 6.36 & 0.57 & 20.73 & 939.71 \\
Clay $\left(\mathrm{T}_{2}\right)$ & 43.39 & 25.36 & 2.30 & 0.26 & 15.75 & 470.3 \\
Gravel $\left(\mathrm{T}_{3}\right)$ & 24.92 & 15.47 & 0.69 & 0.048 & 0.22 & 7.333 \\
Sand :Clay: Silt & & & & & & \\
1:1:1 $\left(\mathrm{T}_{4}\right)$ & 64.72 & 61.02 & 0.55 & 0.055 & 20.00 & 1294.4 \\
1:2:1 $\left(\mathrm{T}_{5}\right)$ & 51.67 & 51.33 & 0.40 & 0.026 & 15.7 & 811.21 \\
2:1:2 $\left(\mathrm{T}_{6}\right)$ & 62 & 54 & 0.46 & 0.037 & 18 & 1116 \\
$2: 2: 1\left(\mathrm{~T}_{7}\right)$ & 59.87 & 43.87 & 0.37 & 0.027 & 14.8 & 881.43 \\
\hline
\end{tabular}

Table 5 - ANOVA analysis for various seedling parameters with various treatments $\left(T_{1}\right.$ to $\left.T_{7}\right)$.

\begin{tabular}{lcccc}
\hline Parameters & $\begin{array}{c}\text { Total Sum of } \\
\text { Square }\end{array}$ & $\begin{array}{c}\text { Mean Sum of } \\
\text { Square }\end{array}$ & $\begin{array}{c}\text { Computed F } \\
\text { Value }\end{array}$ & CD \\
\hline \% Germination & 6506.6 & 1084.4 & $1634.6^{* * *}$ & 13.98 \\
\% Survival & 9200 & 1533.35 & $2115.1^{* *}$ & 14.85 \\
Total Biomass $\left(\mathrm{g} / \mathrm{m}^{2}\right)$ & 84.62 & 14.10 & $557.01^{* *}$ & 2.77 \\
Seedling Quality Index & 0.76 & 0.127 & $2366.7^{* *}$ & 0.247 \\
Average Reproductive Capacity & 1271.5 & 211.9 & $7366.5^{* *}$ & 2.95 \\
Aggressive Capacity & 9448142 & 1574690 & $109862^{* *}$ & 66.05 \\
\hline
\end{tabular}

Significance Level $={ }^{* *} \mathrm{P}>0.001 \%$

Lowest value of seedling parameters in gravel soil could be explained by the habitat preferability of this plant. Studies by Narita (1998) and Mathur and Sundaramoorthy $(2005,2006,2012$ and 2013) have described the sand loving properties of this plant. These finding were not within the agreement of study conducted by Bhandari (1990). However, the inhibitory action of clay soil in different soil mixtures could be explained by the higher moisture retention capacity of clay soil. This property of clay provides more moisture to germinating seed that eventually stimulate the secretion of hydrate mucilage. This hydrate mucilage inhibits the seed germination and other seedling parameters (Mathur 2005). Mathur and Sundaramoorthy (2012) studied the distribution patterns of this species and reported the various transitions in distribution patterns of this species that existed from random pattern to uniform and form random to clumped and uniform distribution patterns. The regression analysis showed that relative importance value of this species were linearly and negatively affected with soil electric conductivity (RIV $=74.95+-255.78$ electric conductivity, $\mathrm{R}^{2}=0.724^{*}, \mathrm{P}$ at $95 \%$ level) and soil phosphorus (RIV $=60.08+-0.84$ soil phosphorus, $\mathrm{R}^{2}=0.724 *, \mathrm{P}$ at $95 \%$ level). They further concluded that soil moisture also affected the Relative Importance Value (RIV $=37.84$ soil moisture ${ }^{{ }^{0.453}}, \mathrm{R}^{2}=0.918^{* *}, \mathrm{P}$ at $99 \%$ level) as well as seed weight negatively in power fashion (seed weight $=0941$ soil moisture ${ }^{-0.10}, \mathrm{R}^{2}=0.91^{* *}$, $\mathrm{P}$ at $99 \%$ level). Thus, this study was also within the agreement of previous study made by author, which was related with spatial distribution pattern of this species.

\section{CONCLUSION}

Beside the habitat loss, evolutionary dispersal trait (delayed seed release) also led the endangerment status of $B$. sindica. Although this species has sufficient reproductive potential for the production of adequate new progeny but in reality, its actual population size is continually decreasing and this contrasting condition is associated with nonsynchronization between the seed dispersal timing and actual ground conditions. The PVA indicated that population one might disappear within 12 years while by adaptation of some of the management option could minimize this threat at a certain level. Serotonious habits in this species provide protection against the predators. However, 
due to this rainfall based sensory mechanism, plants disperse their seed when actual ground conditions (higher moisture) are not suitable for seed germination and survival. Higher sand proportion and moderate moisture conditions were most favourable for its growth. Thus, a speciesspecific conservation prorates is needed to protect this species.

\section{REFERENCES}

Aziz S, Khan, MA. Survivorship pattern of some desert plant. PJB. 1993; 25: 67-72.

Baskin JM, Davis BH, Baskin CC, Gleason SM, Cordell S. Physical dormancy in seeds of Dodonaea viscosa (Sapindales, Sapindaceae) from Hawaii. Seed Sci Res. 2004; 14: 81-90.

Bhandari MM. Flora of Indian Desert. MPS Pro Jodhpur. 1990.

Dickson A, Leaf AI, Honser JE. Seedling quality and soil fertility relationship of white spruce and red fruit in nurseries. Forest Chronicle. 1960; 36: 273-241.

Ellner S, Schmida A. Why are adaptins for long range seed dispersal rare in desert plants?. Oecologia. 1981; 51: 133-144.

Günster A. Seed band dynamics longevity, viability and predation of seeds of serotinous plants in the central Namib Desert. J Arid Environ. 1994; 28: 195205.

Gutterman Y, Ginott S. Long term protected 'seed bank' in dry inflorescences of Asteriscus pygmaeus; achene dispersal mechanism and germination. $J$ Arid Environ. 1994; 26: 149-163.

Gutterman Y. Seed Germination in Desert Plants. Springer Verlag, Berlin. 1993.

Inouye RS, Byers G S, Brown JH. Effects of predation and competition on survivorship, fecundity, and community structure of desert annuals. Ecology. 1980; 61: 1344-1351.

Jacquemyn H, Brys R, Hermy M, Willems JH. Long term dynamics and population viability in one of the last population of the endangered Spiranthes spiralis (Orchidaceae) in the Netherlands. Biol Cons. 2007; 134: 14-21.

Lamont BB, Le Maitre DC, Cowling RM, Enlight NJ. Canopy seed storage in woody plants. Bot Rev. 1991; 57: 277-317.

Ma J, Liu Z, Zeng D, Liu B. Aerial seed bank in Artemisia species: how it responds to sand mobility. Trees 2010; 24. 435-441.

Mathur M. Ecology and Prospecting of Some Medicinal Plants of Aphrodisiac Properties. Ph.D. Thesis. Jai Narain Vyas University, Jodhpur, Rajasthan, India. 2005.
Mathur M. Kinetic of Nutrient Uptake and their Utilization Efficiency in a Seratonious PlantBlepharis sindica. AJBS. 2013; 8: 94-106

Mathur M, Sundaramoorthy S. Germination and seedling quality studies on an aphrodisiac plantBlepharis sindica. In: Proceedings of the International Conference on Multipurpose Trees in Tropics: Assessment, Growth and Management, organised at Arid Forest Research Institute, Jodhpur during 22-25 November. 2005.

Mathur M, Sundaramoorthy S. Ecological and Aphrodisiac properties of Blepharis sindica. Nigerian J Nat Prod Med. 2006; 10: 17-25.

Mathur M, Sundaramoorthy S. Studies on Distribution Pattern for an Endangered Semi-Arid Plant-Blepharis sindica. Vegetos. 2012; 25, 66-75

Morris W, Doak D, Groom M, Kareiva P, Fieberg J, Gerber L, Murph P, Thomson D. A practical handbook for population viability analysis. The Nature Conservancy, Arlington, Virginia. 1999.

Morton SR. Granivory in arid regions: comparison of Australia with North and South America. Ecology. 1985; 66: 1859-1866.

Narita K, Wada N. Ecological significance of the aerial seed pool of a desert lignified annual, Blepharis sindica (Acanthaceae). Plant Ecol. 1998; 135: 177184.

Narita, K. 1998. Effects of seed release timing on plant life-history and seed production in a population of a desert annual, Blepharis sindica (Acanthaceae). Plant Ecol. 136: 195-203.

Peters EM, Martorel C, Ezcurra E. The adaptive value of cued seed dispersal in desert plants: seed retention and release in Mammillaria pectinifera (Cactaceae), a small globose cactus. Am J Bot. 2009; 96: 537-541.

Salisbury EJ. The reproductive capacity of plants. O. Bell and sons LTD. London. 1942.

Saxena SK, Aggarwal RK. Primary productivity and nutrient composition of desert grasses from a common habitat II Grass species. Indian J Ecol. 1983; 312: 205-208

Thanos CA. Bradychory- the coining of a new term, In: Arianoustsou, M., Papanastasis, V.P. (Eds). Proceedings $10^{\text {th }}$ MEDECOS conference, Rhoodes, Greece. Millpress, Rotterdam, pp 1-6. 2004.

Tripathi YC, Arya R. Floral resources of Indian Thar desert. In: (Ed.), Tripathi G. Bio-resource Technology, New Delhi, CBS Publishers and Distributors. 2002; pp. 16-33.

Received: September 26, 2013; Accepted: December 23, 2013. 